\title{
Simulation and manufacturing of a miniaturized Exponential UWB TEM horn antenna for UWB Radar applications
}

\author{
Héctor Dave Orrillo Ascama, Roberto Kenji Hiramatsu, Alexandre M. de Oliveira, Carlos R. P.
} Dionisio, Sergio Takeo Kofuji

Laboratório de Sistemas Integráveis, Universidade de São Paulo, São Paulo, Brasil \{hector, kenji, amanicoba, kofuji\}pad.lsi.usp.br

\begin{abstract}
This paper presents the parameterization of the structure of a miniaturized exponential UWB TEM horn antenna and its effect on the matching impedance and directivity. In addition, a microstrip balun that feeds the antenna was proposed in order to improve the balance, and the return loss for low frequencies. Both the antenna and the microstrip balun were simulated to obtain a final high performance model to be manufactured at a later time. The proposed antenna operates in a frequency range from $3.2 \mathrm{GHz}$ to $7.5 \mathrm{GHz}$, meeting the standards established by the FCC and the ETSI for ultrawideband technology. Moreover, based on these characteristics, the antenna have many $U W B$ radar applications such as monitoring of structures (buildings, bridges, etc.), anti-collision radar, vital signs detection, and long-distance communications, as a result of its high gain around $15 \mathrm{~dB}$.
\end{abstract}

Index Terms - Antenna, Microstrip balun, Transverse Electromagnetic (TEM) horn antenna, Ultra wideband (UWB).

\section{INTRODUCTION}

TEM horn antennas are widely used for transmission and reception of microwave signals due to their high efficiency. They can be employed in applications that require ultra wideband, wide scanning, low cross polarization, directional radiation pattern, and low distortion of pulse transmission [1]. The bandwidth in UWB radars is an essential prerequisite for acquiring high-fidelity pulse radiation. The objective of this work is to obtain an exponential UWB TEM horn antenna with good impedance matching, wideband, high gain and directivity. The antenna presented in this paper was based on the theory of parallel plane waveguide. In the proposed model, these parallel planes were represented by a trapezium-shaped structure whose geometrical parameters varied to find a suitable bandwidth. A balun was added to the exponential UWB TEM horn antenna, aiming at improving the antenna's characteristic impedance and adapting an unbalanced plane line to a balanced one. In most cases, conventional TEM horn antennas are broadband-type. In this work their bandwidth is increased in order to turn them into UWB-type. The basic structure of a horn antenna consists of two parallel planes, as illustrated in Figure 1. The flare angle between the planes is represented by $\beta(0<\beta \leq 180$ $\left.{ }^{\circ}\right)$. Angle $\alpha$ is the opening of the radiation plane $\left(0<\alpha<180^{\circ}\right)$. When $\beta=180^{\circ}$ the structure 
resembles a bow-tie antenna [2]. In this research, we tried to find ideal angles for the design of a TEM horn antenna in order to obtain the constant resistive characteristic impedance of the spherical wave TEM $\left(\mathrm{E}_{\mathrm{r}}=\mathrm{H}_{\mathrm{r}}=0\right)$ along parameter $s$, when $s \rightarrow \infty$.

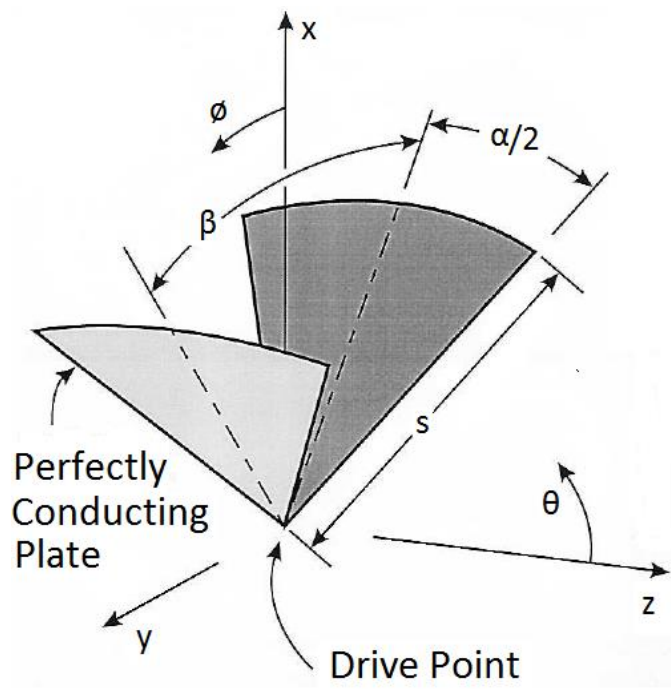

Fig. 1. Structure of a TEM Horn antenna Erro! Fonte de referência não encontrada.

In current literature, much research was carried out to create horn antennas and additional components. A microstrip balun is used in a large TEM horn antenna designed to perform EMC measurements [3]. A large TEM horn antenna attached to a cylindrical feed section that helps obtaining good return loss values, but with the disadvantage of showing low gain (maximum value of $13 \mathrm{~dB}$ for high frequencies) was reported in [4]. In [5] is shown an exponential TEM horn antenna with binomial radiation planes presenting directional radiation patterns, but to the detriment of gain (less than $9.5 \mathrm{~dB}$ ) across the entire UWB band.

In the present work, an exponential TEM horn antenna is simulated and constructed. Its performance (impedance matching, gain and directivity) is assessed by changing the microstrip balun [3]. Design details of the TEM horn antenna and microstrip balun are explained in the following sections.

\section{ANTENNA DESIGN}

The TEM horn antenna design has two exponential metal planes operating as electromagnetic radiators. The size and length of these planes were carefully chosen to give an ultra wideband characteristic for the antenna. The entire design consists of two sections: the radiation planes design and the microstrip balun design, as seen in Figure 2. 


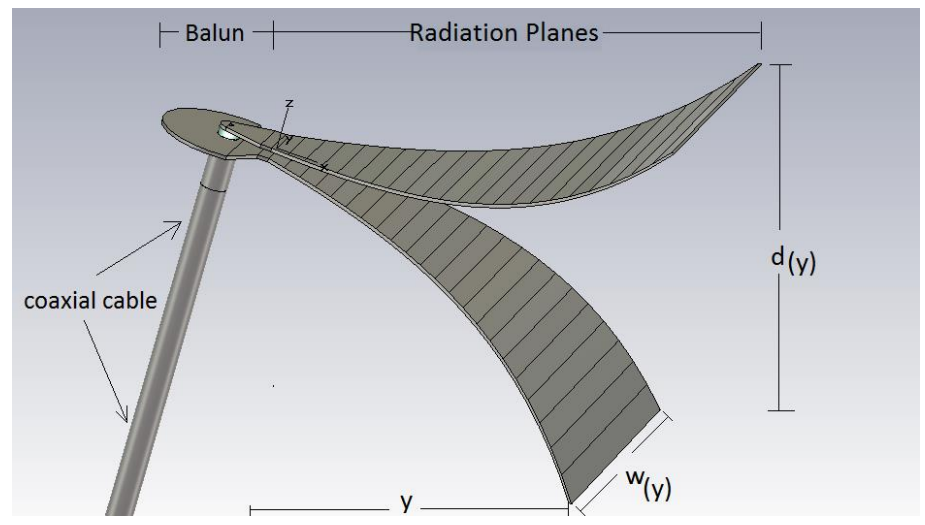

Fig. 2. View of the components of a TEM Horn antenna: Radiation planes and microstrip balun.

\section{A. Radiation planes design}

The radiation planes of the proposed UWB TEM horn antenna are exponential-type. Such exponential structure has the advantage of reducing the reflections of the travelling electromagnetic wave. As shown in equation 1, the distance between the radiation planes is estimated in [4];

$$
\mathrm{S}(\mathrm{y})=2\left\{\mathrm{ae}^{\mathrm{by}}\right\}, 0 \leq \mathrm{y} \leq \mathrm{L}
$$

where $\mathrm{S}(\mathrm{y})$ is an exponential function that represents the separation between both radiation planes; (a) and (e) are the initial and the final separation of the radiation planes, respectively; and L is the antenna length. The exponential planes are used to achieve good impedance matching in the feed line $(50 \Omega)$ and at the antenna aperture $(377 \Omega)$. The characteristic impedance at any point in the structure of the TEM horn antenna can be calculated by the following equation [5].

$$
\mathrm{Z}(\mathrm{y})=\mathrm{Z}_{0} * \mathrm{e}^{\alpha \mathrm{y}}, \quad 0 \leq \mathrm{y} \leq \mathrm{L}
$$

where:

$$
\begin{gathered}
\mathrm{Z}_{0}=50 \Omega \\
\alpha=\frac{1}{\mathrm{~L}} \ln \left(\frac{120 \pi \Omega}{50 \Omega}\right)
\end{gathered}
$$

Its output impedance was calculated by equation [4], where $d(y)$ is the separation between both planes, and $\mathrm{w}(\mathrm{y})$ is the width of the antenna's radiation plane.

$$
\mathrm{Z}(\mathrm{y})=120 \pi * \frac{\mathrm{d}(\mathrm{y})}{\mathrm{w}(\mathrm{y})}
$$




\section{B. Microstrip balun design}

This section presents the changes made to the microstrip balun proposed in [3]. They were aimed at obtaining low values for parameter $\mathrm{S}_{11}$, directional radiation patterns, and high gain in the TEM horn antenna. The design structure of the microstrip balun proposed in this work is shown in more detail in Figures 3 and 4 . The results are exhibited in section III.

The main objective of the microstrip balun design is to have a good impedance matching between the input impedance of the TEM horn antenna and the output impedance of the microstrip balun. The characteristic impedance at any point in the microstrip balun was calculated by equation [6],

$$
\mathrm{k}(\mathrm{y})=\frac{120 \pi}{\left[\frac{\mathrm{W}(\mathrm{y})}{\mathrm{h}}+1.393+0.667 \mathrm{l} \mathrm{n}\left(\frac{\mathrm{W}(\mathrm{y})}{\mathrm{h}+1.444}\right)\right]}
$$

with

$$
\frac{\mathrm{W}(\mathrm{y})}{\mathrm{h}} \geq 1
$$

Where $\mathrm{W}(\mathrm{y})$ is the width of the radiation plane, and $h$ is the separation between the two planes comprising the balun. The dimensions of the structure of the microstrip balun can be calculated using equations (2) and (5).

Furthermore, the proposal of this work included an insulating material FR4, as shown in Figure 4. The analysis eventually found that such material helped obtaining better values for parameter $\mathrm{S}_{11}$, and higher directivity at low frequencies (this is the aim of our study).

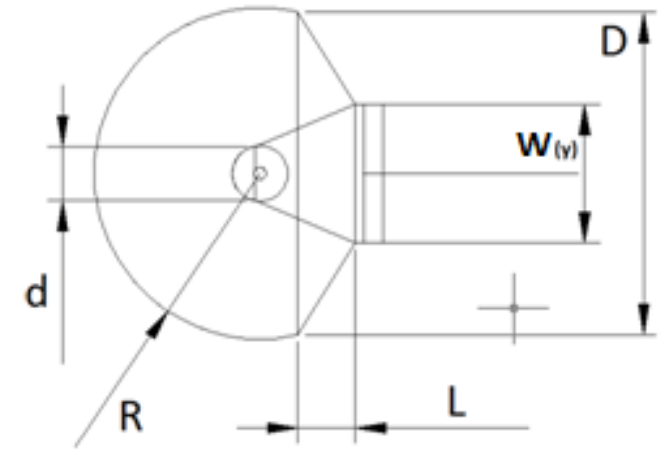

(a) Top view

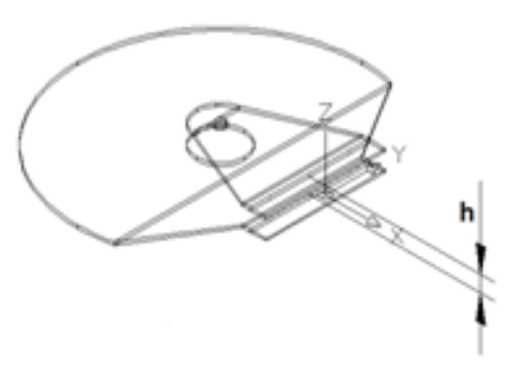

(b) Side view

Fig.3. Structure of the proposed microstrip balun. 


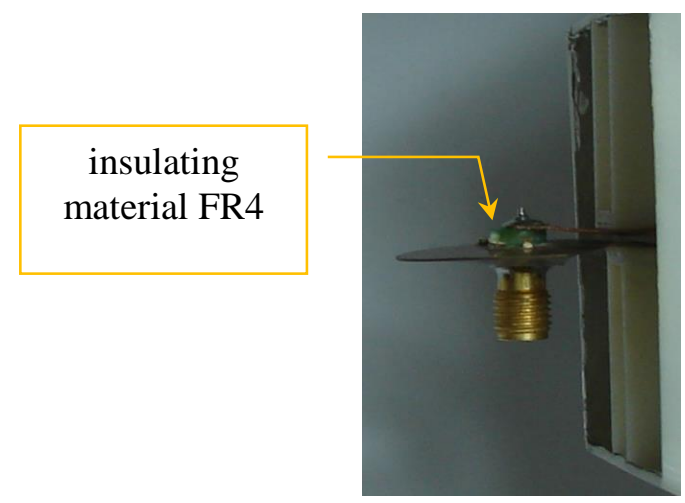

Fig.4. Photograph of the proposed microstrip balun.

\section{SIMULATIONS AND MEASUREMENTS}

Radiation planes and the microstrip balun, comprising the structure of the TEM horn antenna, were designed and optimized using the electromagnetic simulation software $C S T M W S^{1}$. The model of the microstrip balun is shown in Figures 3 and 4, whereas the manufactured and simulated model of the proposed antenna can be seen in Figure 5.

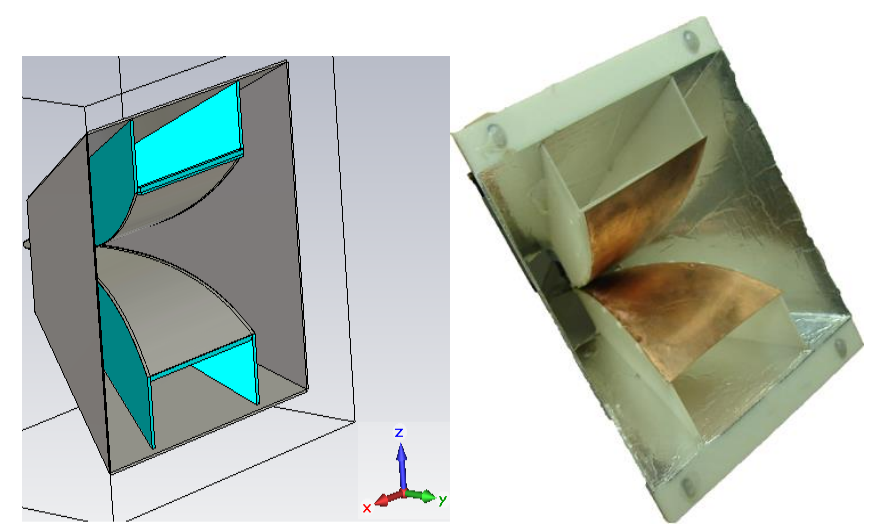

Fig.5. Simulated and manufactured prototype of the UWB TEM horn antenna.

Figure 6 shows that the top view of the antenna's radiation plane is a trapezium. Therefore, as a result of this particular geometry, we could obtain value w(y). Values for the distance between the planes $\mathrm{d}(\mathrm{y})$ are calculated in equation 5 . 


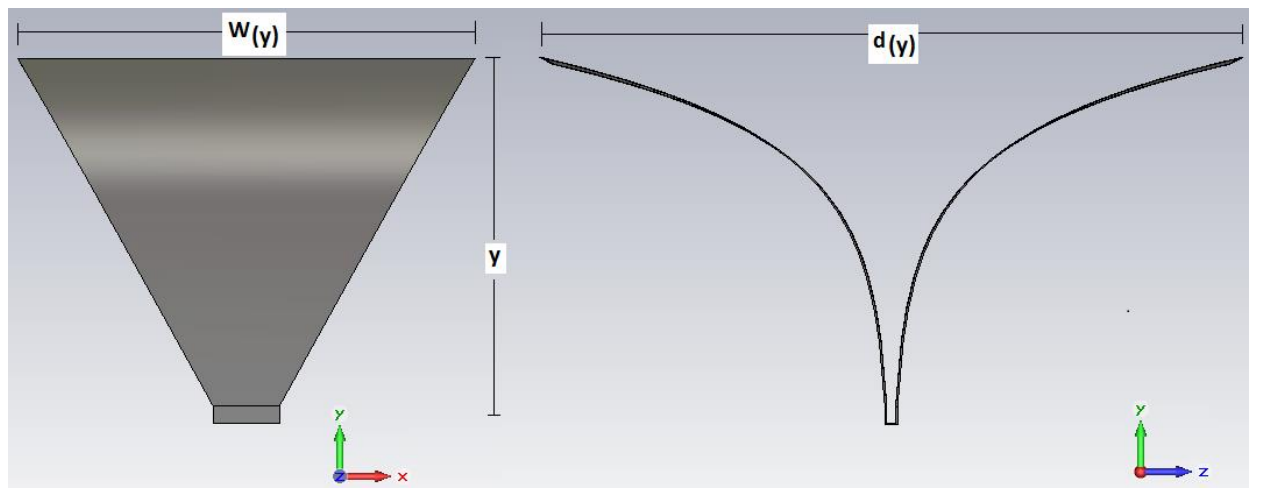

Fig.6. Top view and side view of the radiation planes of the UWB TEM horn antenna.

Table I shows the dimensions of the exponential TEM horn antenna that has a better impedance matching, high gain and directivity.

TABLE I. DIMENSIONS OF THE UWB TEM HORN ANTENNA.

\begin{tabular}{ccccc}
\hline Number of section & $\mathbf{y}(\mathbf{m m})$ & $\boldsymbol{Z}_{(\boldsymbol{y})}(\boldsymbol{\Omega})$ & $\mathbf{d}_{(\mathbf{y})}(\mathbf{m m})$ & $\mathbf{w}_{(\mathbf{y})}(\mathbf{m m})$ \\
\hline 0 & 0,0 & 50,0 & 1,5 & 11,3 \\
1 & 16,5 & 74,9 & 4,8 & 24,0 \\
2 & 33,0 & 112,2 & 10,9 & 36,8 \\
3 & 49,5 & 168,0 & 22,1 & 49,5 \\
4 & 66,0 & 251,7 & 41,6 & 62,3 \\
5 & 82,5 & 377,0 & 75,0 & 75,0 \\
\hline
\end{tabular}

Figure 5 shows the manufactured antenna. Its structure has a total length of $103.8 \mathrm{~mm}$, and the distance between the radiation planes in the microstrip region is $1.5 \mathrm{~mm}$. The proposed antenna was built on a copper plate with a thickness of $0.3 \mathrm{~mm}$ and a permissibility $\left(\Sigma_{\mathrm{r}}\right)$ of 4.3 . FR4 plates were used to support the radiation planes.

Figure 7 shows the group delay simulated and measured. Group delay is the derivative of the antenna phase. If the phase is linear, it would be desirable that group delay values varied over the minimum time interval at the antenna's operating frequency. This characteristic indicates the transmission quality of an ultra-wideband pulse and its degree of distortion or dispersion.

Figure 8 shows the simulated and measured VSWR value for a proposed exponential UWB TEM horn antenna. The antenna has VSWR $\leq 2$ from $3.2 \mathrm{GHz}$ to $7.5 \mathrm{GHz}$, which means that it exhibits minimal reflections, and the received signal can be transmitted with maximum efficiency. This value is also a necessary condition for an ultra-wideband antenna. 


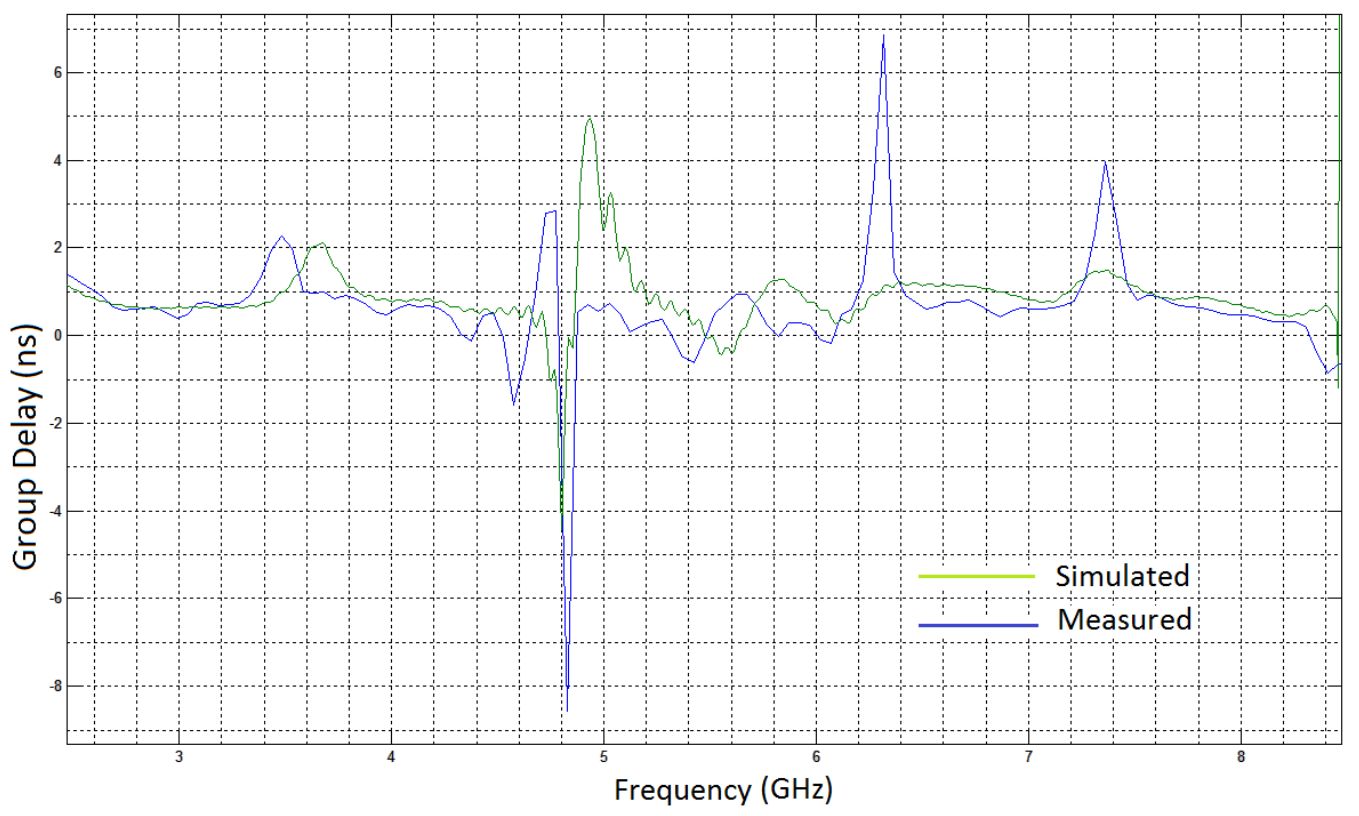

Fig.7. Simulated and measured group delay of UWB TEM horn antenna.

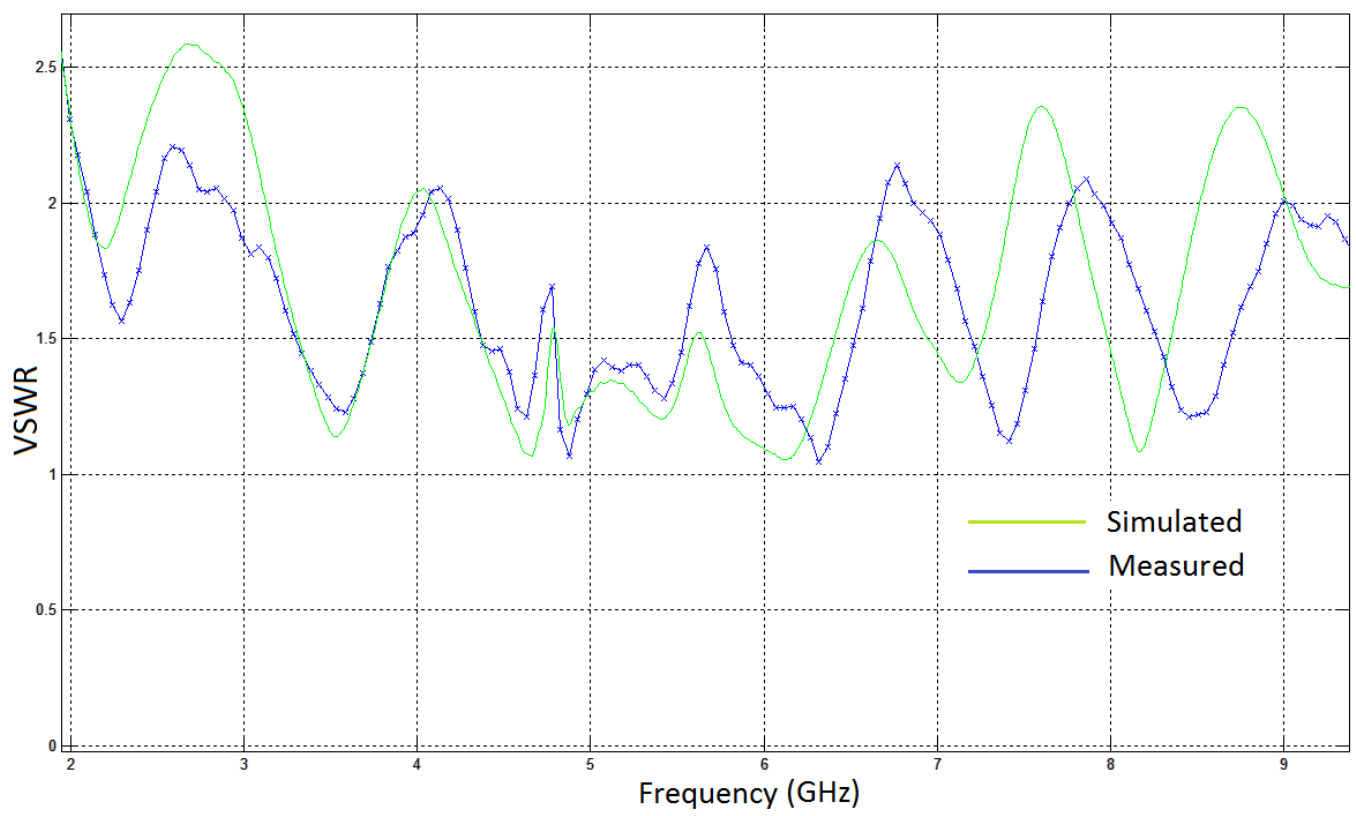

Fig.8. Simulated and measured VWSR of UWB TEM horn antenna.

Figure 9 shows simulated and measured values for parameter $S_{11}$. Those obtained through the use of insulating material show lower rates of reflected power at frequencies between $3.2 \mathrm{GHz}$ and $6.6 \mathrm{GHz}$. It can be noticed that the value for signal return due to mismatch is lower when compared to those obtained without use of insulating material. 


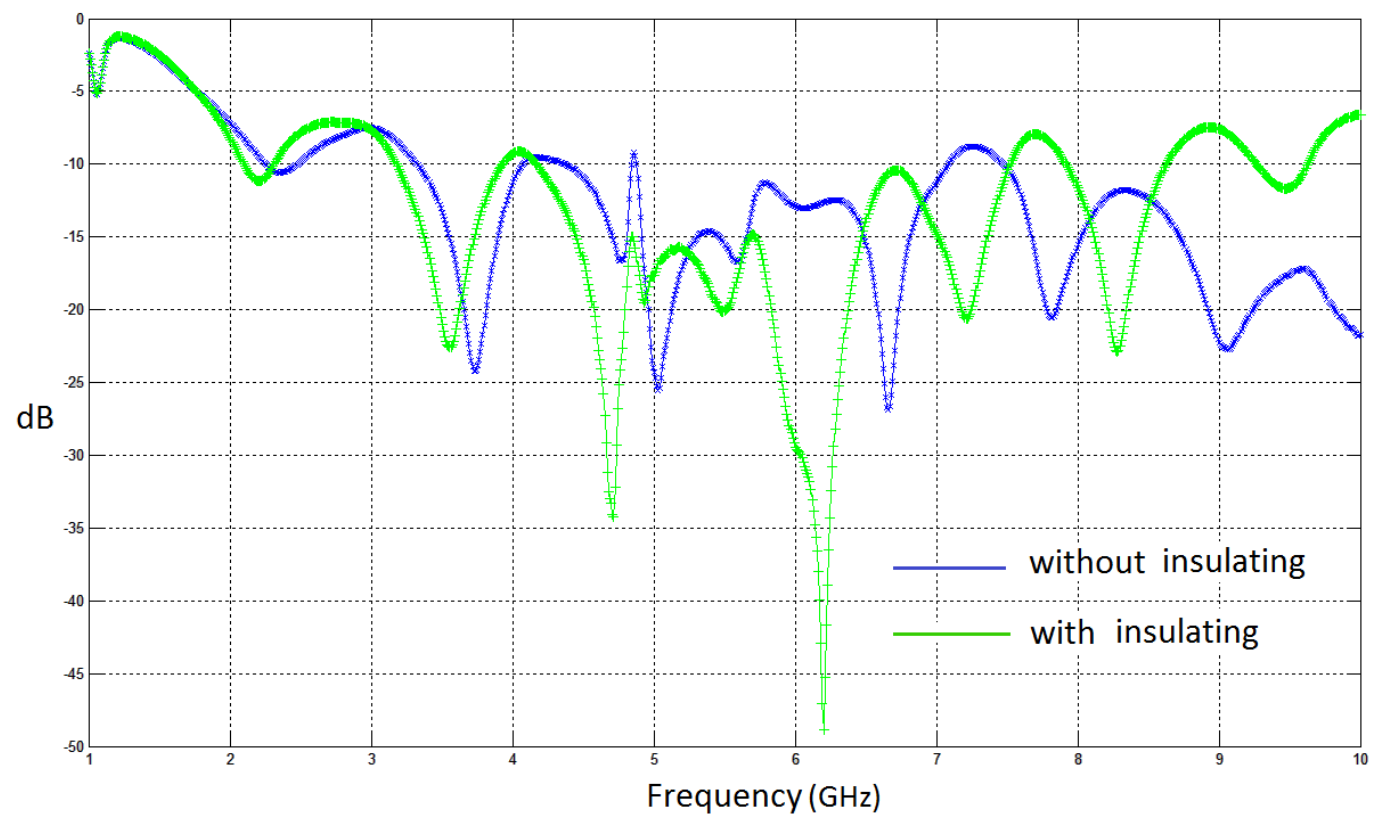

Fig.9. Simulated and measured $\mathrm{S}_{11}$ of UWB TEM horn antenna.

Distance from junction (L) is defined as the distance from the centre region of the coaxial connection to the antenna's signal input end. Equation (7) determines L of microstrip balun, $\lambda$ is the wavelength at the lowest operating frequency of the TEM horn antenna [7].

$$
\mathrm{L}=0.478 \lambda
$$

According to equations (2) and (6), it was conducted a preliminary measurement of the dimensions of the microstrip balun using CST. Such dimensions were optimized in order to obtain a good impedance matching between the input impedance of the proposed TEM horn antenna and the output impedance of the microstrip balun. After performing several tests, we concluded that the length $\mathrm{L}$ of the microstrip balun affects the antenna performance. When $\mathrm{L}$ is small, radiation pattern is not very directional. When $\mathrm{L}$ is large, reflection effect affects the performance of parameter $S_{11}$. The final dimensions are: $\mathrm{R}=13.5 \mathrm{~mm}, \mathrm{~d}=4.41 \mathrm{~mm}, \mathrm{~L}=4.65 \mathrm{~mm}, \mathrm{w}_{(\mathrm{y})}=11.25 \mathrm{~mm}, \mathrm{D}=26.18 \mathrm{~mm}, \mathrm{~h}=1.48$ mm. See Figure 3.

Figure 10 shows radiation diagrams simulated in continuous red and measured in blue at four different frequencies: $3.5 \mathrm{GHz}, 4.5 \mathrm{GHz}, 5 \mathrm{GHz}$, and $6 \mathrm{GHz}$. 


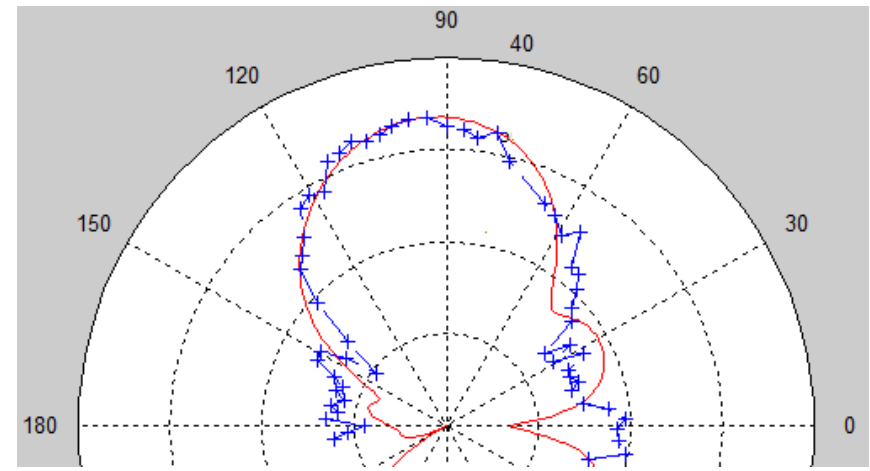

(a) $3.5 \mathrm{GHz}$

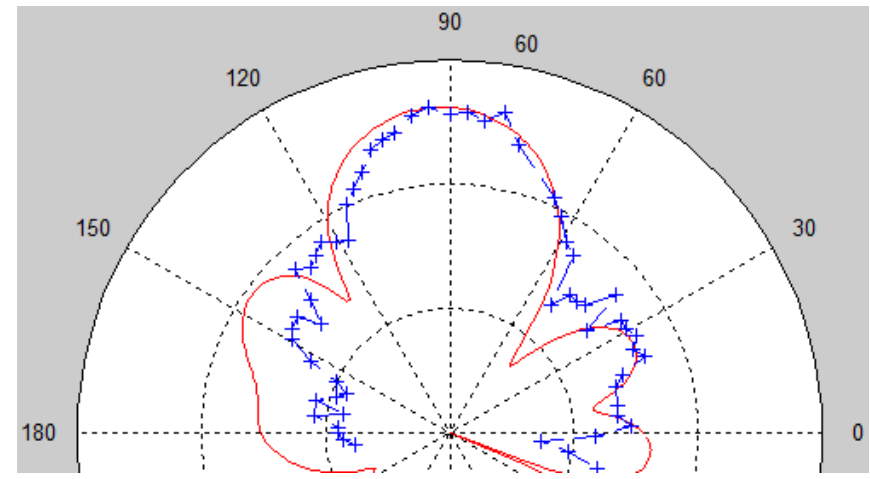

(b) $4.5 \mathrm{GHz}$

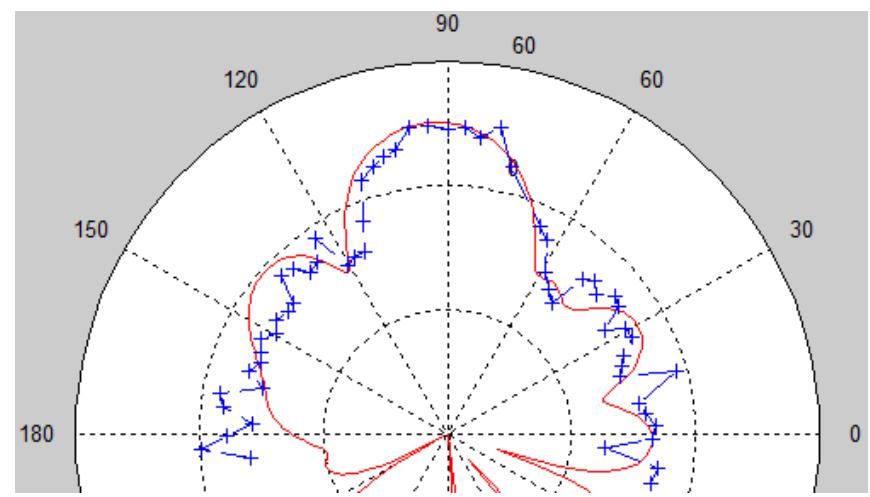

(c) $5 \mathrm{GHz}$

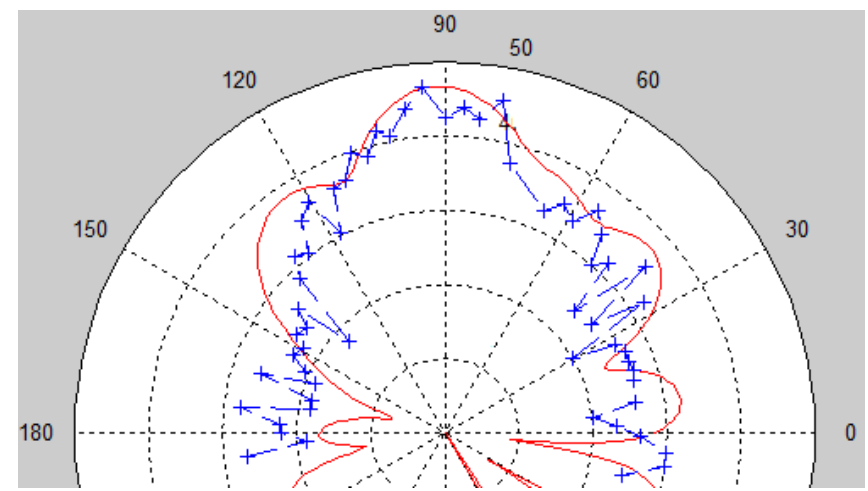

(d) $6 \mathrm{GHz}$

Fig.10. Radiation diagram (plane y-z) of the proposed antenna at $3.5 \mathrm{GHz}, 4.5 \mathrm{GHz}, 5 \mathrm{GHz}$, and $6 \mathrm{GHz}$. 
It can be observed in all cases that the simulated and measured radiation patterns are similar. They follow a directional pattern at all given frequencies.

Figure 11 shows the comparison between antenna gains with and without metallic reflectors. We notice that from $4 \mathrm{GHz}$ to $6.5 \mathrm{GHz}$ the antenna achieves a gain higher than $14 \mathrm{~dB}$ when using reflectors.

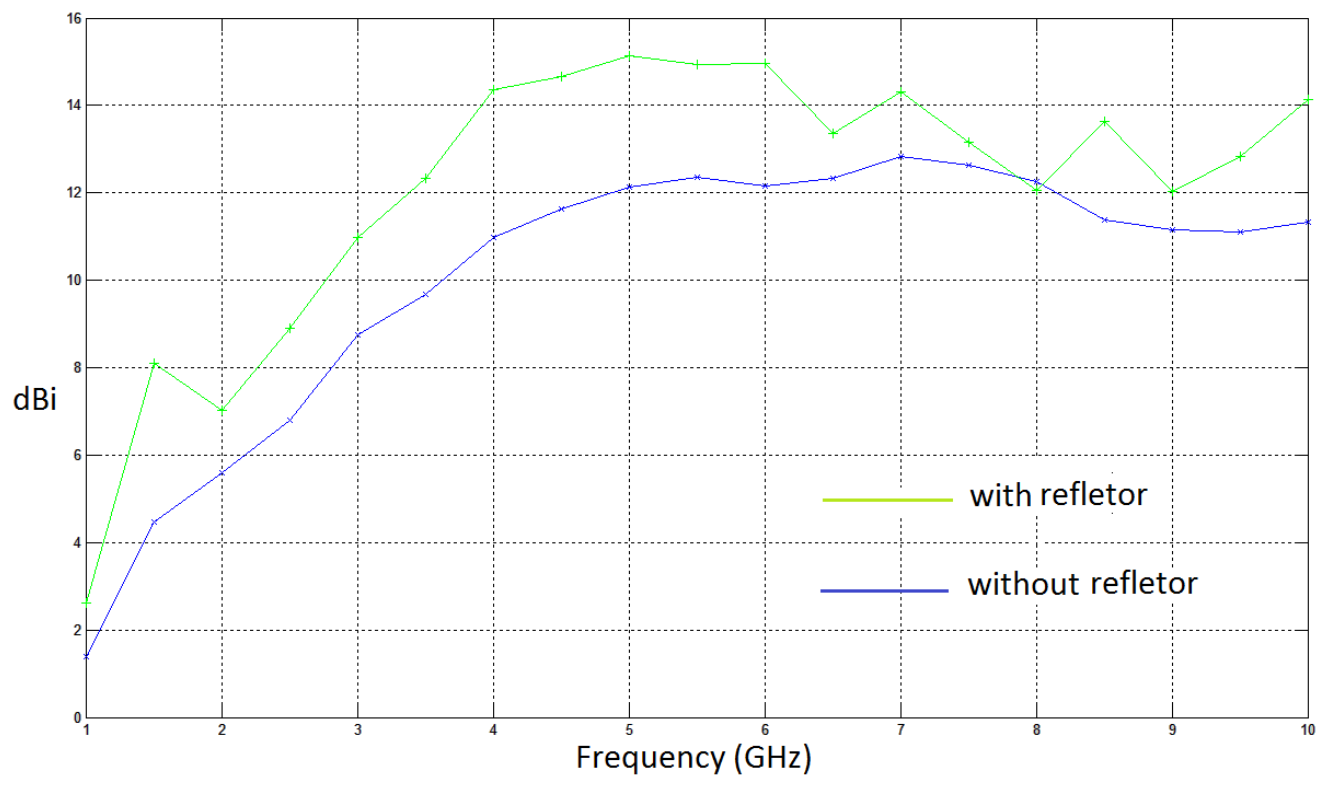

Fig.11. Gain of proposed UWB TEM horn antenna.

\section{CONCLUSIONS}

This paper presents a miniaturized exponential UWB TEM horn antenna and a microstrip balun. Both proposals were simulated and manufactured at a later time. Their measurements show good impedance matching, high directivity, constant balancing, and return loss $\leq-10 \mathrm{~dB}$ for the 3.2-7.5 $\mathrm{GHz}$ frequency band. The aforementioned antenna is an ideal potential candidate for being used in applications of UWB radar and long-distance communications due to its high gain values around 15 $\mathrm{dB}$.

\section{ACKNOWLEDGMENTS}

Dr. Héctor Dave Orrillo Ascama and Dr. Carlos R. P. Dionisio thank PNPD / CAPES for their financial aid to this work. Dr. Roberto Kenji thanks Flexmedia for their technical support in the development of a new antenna model.

\section{REFERENCES}

[1] Y. Najjar, M. Moneer, N. Dib. "Design of Optimum Gain Pyramidal Horn with Improved Formulas Using Particle Swarm Optimization". in Int J RF and Microwave CAE 17, pp.505-511, June 2007.

[2] R. Todd Lee and Glenn S. Smith. "On the Characteristic Impedance of the TEM Horn Antenna". IEEE Transactions on antennas and propagation. Vol. 52, $\mathrm{N}^{\circ}$. 1, January 2004.

[3] Chung, K., S. Pyun and J. Choi. "Design of an ultrawide-band TEM horn antenna with a microstrip-type balun". IEEE Trans. Antennas and Propag.,V ol. 53,No. 10,3410-3413, October 2005. 
[4] F. Karshenas, A. R. Mallahzadeh, and A. Imani. "Modified TEM Horn Antenna for Wideband Applications". 13th International Symposium on Antenna Technology and Applied Electromagnetics and the Canadian Radio Sciences Meeting, April 2009.

[5] Mohammadreza Khorshidi and Manouchehr Kamyab. "New exponential TEM horn antenna with binomial impedance taper". AEU - International Journal of Electronics and Communications. Elsevier B.V. 2009.

[6] D. M. Pozar, Microwave Engineering, 2nd Ed . New York:Wiley, 1998, pp. 160-167.

[7] J. W. Duncan and V. P. Minerva. "100:1 Bandwidth Balun Transformer". IRE Proc., vol. 48, February 1960, pp. 156164. 